\title{
Sophocarpine Attenuates LPS-Induced Liver Injury and Improves Survival of Mice through Suppressing Oxidative Stress, Inflammation, and Apoptosis
}

\author{
Zhengyu Jiang $(\mathbb{D}$, Yan Meng, Lulong Bo, Changli Wang, Jinjun Bian $\mathbb{D}$, \\ and Xiaoming Deng $(\mathbb{D}$ \\ Faculty of Anesthesiology, Changhai Hospital, Second Military Medical University, 200433 Shanghai, China \\ Correspondence should be addressed to Jinjun Bian; jinjunbicu@163.com and Xiaoming Deng; deng_x@yahoo.com
}

Zhengyu Jiang and Yan Meng contributed equally to this work.

Received 8 January 2018; Accepted 18 March 2018; Published 16 May 2018

Academic Editor: Danilo Vojvodic

Copyright (C) 2018 Zhengyu Jiang et al. This is an open access article distributed under the Creative Commons Attribution License, which permits unrestricted use, distribution, and reproduction in any medium, provided the original work is properly cited.

Septic liver injury/failure that is mainly characterized by oxidative stress, inflammation, and apoptosis led to a great part of terminal liver pathology with limited effective intervention. Here, we used a lipopolysaccharide (LPS) stimulation model to simulate the septic liver injury and investigated the effect of sophocarpine on LPS-stimulated mice with endotoxemia. We found that sophocarpine increases the survival rate of mice and attenuates the LPS-induced liver injury, which is indicated by pathology and serum liver enzymes. Further research found that sophocarpine ameliorated hepatic oxidative stress indicators $\left(\mathrm{H}_{2} \mathrm{O}_{2}, \mathrm{O}_{2}^{--}\right.$, and $\mathrm{NO}$ ) and enhanced the expression of antioxidant molecules such as superoxide dismutase (SOD), catalase (CAT), and glutathione (GSH). In addition, sophocarpine also attenuated regional and systematic inflammation and further reduced apoptosis of hepatocytes. Mechanistic evidence was also investigated in the present study as sophocarpine inhibited hepatic expression of the CYP2E/Nrf2 pathway during oxidative stress, inactivated p38/JNK cascade and NF- $\kappa \mathrm{B}$ pathway, and, meanwhile, suppressed PI3K/AKT signaling that reduced apoptosis. Conclusively, the present study unveiled the protective role of sophocarpine in LPS-stimulated oxidative reaction, inflammation, and apoptosis by suppressing the CYP2E/Nrf2/ROS as well as PI3K/AKT pathways, suggesting its promising role in attenuating inflammation and liver injury of septic endotoxemia.

\section{Introduction}

The liver plays a key role in immunological homeostasis and metabolism [1] while these crucial functions are usually impaired by lipopolysaccharide (LPS), inflammatory factors, and pathogens $[2,3]$. LPS presents the major component of endotoxin in gram-negative bacteria and causes uncontrolled production of inflammatory mediators and oxidative stress, resulting in acute liver injury (and failure) [4]. LPS-induced liver injury in mice has been employed as a model for molecular pathological research [5], simulating the course of liver damage and failure in septic endotoxemia or sometimes septic shock or death $[2,6]$. Liver failure is characterized by hepatic encephalopathy and disorder of protein synthesis [6]. Though specific mechanism remains controversial, consensus has been well reached that hepatic inflammatory oxidative stress and apoptosis might be the crucial mechanism.

Sepsis progression and septic liver dysfunction present complex pathophysiological alterations, [7], including processes like releasing of reactive oxygen species (ROS), nitrogen species (RNS), inflammation, and apoptosis. Characterized by the imbalance of endogenous enzymatic activity, such as catalase (CAT), superoxide dismutase (SOD), and glutathione (GSH) $[8,9]$, oxidative damage could be reflected by CYP2E1, which promotes the production of ROS during its catalytic cycle and may be the main contributor to oxidative stress and liver injury [10-12]. Thus, antioxidant compounds have been considered a promising treatment against ROS-induced liver injury or failure [13]. 
Additionally, oxidative stress is able to activate the p38 MAPK pathway, resulting in the activation of mitochondrialrelated or other apoptotic pathways $[14,15]$. In addition to the well acknowledged notion that phosphatidylinositol 3 kinase (PI3K)/Akt signaling as a key modulator of apoptotic process $[16,17]$, recent research proposed AKT could regulate apoptosis-related proteins including Bax, caspase-9, and caspase-3, which are also crucially involved in anticancer drugstimulated apoptosis of cancer cells [18]. Nevertheless, the potential role of PI3K/AKT in liver injury remains unclear.

Liver injury induced by LPS is associated with inflammatory mediators including superoxide, nitric oxide, and tumor necrosis factor (TNF- $\alpha$ ), interleukin- $\beta$ (IL- $1 \beta)$, interleukin6 (IL-6), and other cytokines $[19,20]$. LPS may activate the transcription factor nuclear factor-kappa B (NF- $\kappa \mathrm{B})$ leading to activation of many inflammatory genes, such as TNF- $\alpha$ and IL-1 $\beta$ [19-21]. Therefore, inactivation of NF- $\kappa$ B could attenuate LPS-induced sepsis and liver injury or liver failure.

Sophora alkaloids, such as sophocarpine, are able to be separated from the traditional Chinese herbs, for example, Sophora flavescens and Sophora alopecuroides [22, 23]. It has been reported that the extracts of Sophora alopecuroides, named Kudouzhi injection in clinical, have been used for the treatment of inflammation, pain, edema, and fever [23]. Furthermore, sophocarpine, called Kangke injection in clinical, has been employed to inhibit viral replication [24]. Sophocarpine also shows its activity against inflammation [23], and it suppresses inflammatory processes by inhibiting the JNK pathway, p38 MAPK pathway, and NF- $\kappa$ B pathway, reducing the levels of iNOS and COX-2 [25]. However, the mechanisms underlying the role of sophocarpine remains unknown in LPS-induced liver injury.

In the present study, sophocarpine improved the liver function and protected the liver from inflammatory liver injury. To investigate its molecular mechanisms, the role of NF- $\kappa \mathrm{B}, \mathrm{PI} 3 \mathrm{~K} / \mathrm{AKT}$, and CYP2E/Nrf2/ROS had been determined in acute liver injury. In the end, we evaluated the effects of sophocarpine on oxidative stress-associated apoptosis and inflammation in LPS-induced mice.

\section{Materials and Methods}

2.1. Cell Culture and Reagents. The hepatic stellate cells (HSCs) were purchased from ATCC (American Type Culture Collection, Manassas, VA, USA) and cultured in DMEM media supplemented with $100 \mathrm{U} / \mathrm{mL}$ penicillin and $100 \mathrm{mg} / \mathrm{mL}$ streptomycin (Gibco, Waltham, MA, USA) and $10 \%$ fetal bovine serum (FBS) (Gibco, Waltham, MA, USA) in a humidified incubator containing $5 \% \mathrm{CO}_{2}$ and $95 \%$ air at $37^{\circ} \mathrm{C}$. The HSCs were incubated with LPS $(100 \mathrm{ng} / \mathrm{mL})$ in the absence or presence of sophocarpine at the concentration of $1 \mu \mathrm{M}$ and $2 \mu \mathrm{M}$ about $24 \mathrm{~h}$. These cells were used for the further studies.

2.2. Animals. Eight-week-old C57 BL/6 male mice, about $22.1 \mathrm{~g}$ per mouse, were employed for further study. And these mice were bought from the Experimental Animal Centre of Second Military Medical University (Shanghai, China) and were approved by the Animal Care and Use Committee of
Changhai Hospital, Second Military Medical University (Shanghai, China). They were placed in a specific pathogenfree (SPF) room with sawdust bedding at a temperature of $25-26^{\circ} \mathrm{C}$ and a relative humidity of $\sim 50 \%$ and light $12 \mathrm{~h} /$ day, and water and food were free to access. The authors confirmed that all animals received human care, and all animal experiments were conducted in accordance with the relevant guidelines and regulations. In this study, the normal mice were starved about 16 hours and they were divided randomly into four groups: con (control), LPS-induced group, and LPS-induced mice pretreated with sophocarpine $(30 \mathrm{mg} /$ $\mathrm{kg}$ body weight per day and $60 \mathrm{mg} / \mathrm{kg}$ body weight per day). For the establishment of liver injury in LPS-administrated mice with endotoxemia, the mice were injected intraperitoneally with LPS ( $5 \mathrm{mg} / \mathrm{kg}$ body weight) and we prepared 30 mice for each group above. Sophocarpine was administered orally once at 16:00 17:00 every day for 24 days. Meanwhile, we marked the number of dead mice for each group.

2.3. Analyses of Liver Function. Performed as the indicators of hepatic function, serum and liver levels of glutathione (GSH), alanine transaminase (ALT), alkaline phosphatase (ALP), and aspartate transaminase (AST) were analyzed by employing the biochemical kits from R\&D Systems (Minneapolis, MN, USA).

2.4. Analyses of $\mathrm{H}_{2} \mathrm{O}_{2}$ and $\mathrm{O}_{2}^{--}$Production and ROS Levels in Liver of Mice. Hepatic levels of $\mathrm{O}_{2}^{\bullet-}$ were measured using the chemiluminescence method [26]. Firstly, the weighed liver tissues of mice were homogenized in lysis buffer, $\mathrm{pH} 7.4$, containing $10 \mathrm{mM}$ EDTA as well as $20 \mathrm{mM}$ HEPES. The samples were centrifuged for $10 \mathrm{~min}$ at $1000 \mathrm{~g}$, and, then, the aliquot of samples was incubated with a Krebs-HEPES buffer, $\mathrm{pH} 7.4$, containing $5 \mathrm{mM}$ lucigenin (Sigma, Shanghai, China) about $2 \mathrm{~min}$ at $37^{\circ} \mathrm{C}$. Next, light emission data were obtained on a M200 PRO multifunctional microplate reader (TECAN, Switzerland), and the results were showed as mean light unit (MLU) $\mathrm{min} / \mathrm{mg}$ protein. Levels of $\mathrm{O}_{2}^{--}$were measured by adding SOD $(350 \mathrm{U} / \mathrm{mL})$ to the medium according to the manufacturer's instruction (R\&D Systems, Minneapolis, MN, USA). In addition, liver tissues were homogenized in normal saline, and the samples were treated with equal volume of cold methanol for $60 \mathrm{~min}$ in a $4^{\circ} \mathrm{C}$ icebox. Then, the samples were centrifuged for half an hour at $10000 \mathrm{~g}$ and we obtained the supernatant for $\mathrm{H}_{2} \mathrm{O}_{2}$ evaluation using the biochemical kits from the R\&D Systems (Minneapolis, MN, USA). Protein concentration was measured using the Bradford method, and BSA was employed as the standard.

2.5. Determination of IL-1 $\beta, T N F-\alpha$, and IL-16 by ELISA. The weighed liver tissues were put in a cold PBS buffer ( $\mathrm{pH} 7.0)$ containing $0.002 \%$ sodium acid, $0.1 \mathrm{mg} / \mathrm{mL}$ soybean trypsin inhibitor, $2 \mathrm{mM}$ PMSF, $10 \mathrm{nM}$ EDTA, and $1.0 \mathrm{mg} / \mathrm{mL}$ BSA. The tissues were homogenated, and, then, the samples were incubated for $2 \mathrm{~h}$ in a $4^{\circ} \mathrm{C}$ refrigerator. For further assays, the supernatants were collected by centrifugation at $12000 \mathrm{~g}$ for $10 \mathrm{~min}$. IL- $1 \beta$, TNF- $\alpha$, and IL-16 levels in the supernatant of the serum and liver were measured using ELISA kits (Sigma, Shanghai, China). 
2.6. Hematoxylin-Eosin Staining. The liver tissues from mice were fixed in $10 \%$ formalin, and the fixed specimens were processed to paraffin blocks, sectioned $(5 \mu \mathrm{m})$, and stained with hematoxylin-eosin (H\&E) for histological analysis according to the standard protocols [27]. In this study, the sections were observed in a blind manner [27].

2.7. Reverse Transcription Polymerase Chain Reaction (RT$P C R)$. The reverse transcription polymerase chain reaction (RT-PCR) and the quantitative real-time PCR (Q-PCR) were performed as previously described [20]. Total RNA was extracted from liver tissues and HSCs using TRIzol reagent from Thermo Fisher Scientific (Waltham, MA, USA). The cDNA was obtained by reverse transcription in a $20 \mu \mathrm{L}$ reaction containing $2 \mu \mathrm{g}$ of total RNA, oligo (dT), and reverse transcription premix.

The quantitative real-time PCR (Q-PCR) reactions were performed with the SYBR green PCR system in an ABI 7500 thermal cycler (Thermo Fisher Scientific, Waltham, MA, USA). The SYBR green reagents were also purchased from Thermo Fisher Scientific. The cycling conditions were as follows: $95^{\circ} \mathrm{C}$ for $3 \mathrm{~min}$; followed by 40 cycles involving denaturing at $95^{\circ} \mathrm{C}$ for $10 \mathrm{~s}$, annealing at $60^{\circ} \mathrm{C}$ for $5 \mathrm{~s}$, and extension at $72^{\circ} \mathrm{C}$ for $10 \mathrm{~s}$. Expression of mRNAs was normalized by the mRNA levels of $\beta$-actin, which was used as an internal control. The primers were shown here are PI3K, sense, $5^{\prime}$-TGACAGTAGGAGGAGGTTGG-3', antisense, $5^{\prime}$-TCAGCCACATCAAGTATTGG-3'; AKT, sense, $5^{\prime}$-GA AGGTGATTCTGGTGAAAGAG-3', antisense, $5^{\prime}$-ACAC GGTTCTCAGTAAGCG-3'; caspase-9, sense, $5^{\prime}$-TCTT CATCTCCTGCTTAGAGG-3', antisense, $5^{\prime}$-TGCTCCTTT GCTGTGAGTC- $3^{\prime}$; caspase- 3 , sense, $5^{\prime}$-TGGAAAGCCGA AACTCTTC-3', antisense, $5^{\prime}$-AGGAATAGTAACCAGGT GCTG-3'; caspase-6, sense, 5'-AGCGCGTACTTAAATG CAGAGG-3', antisense, $5^{\prime}$-GTTGTAAGGTGGACAGGCT T-3'; Cyto-C, sense, $5^{\prime}$-CAGACAAGAAGAGGTTGCC-3', antisense, 5'-CGTCATGGCAGTGTGTATTGG-3'; Bad, sense, $5^{\prime}$-CAGAGTTTGAGCCGAGTGAG-3', antisense, $5^{\prime}$-TCCCTGCTGATGAATGTTG-3'; Bcl-xL, sense, $5^{\prime}$-GCA GGCGATGAGTTTGAAC-3', antisense, $5^{\prime}$-TCCTTGTCT ACGCTTTCCAC- $3^{\prime}$; GAPDH, sense, $5^{\prime}$-CATTCAAGACC GGACAGAGG-3', antisense, $5^{\prime}$-ACATACTGCACACCAG CATCACC- $3^{\prime}$. In the end, we analyzed the relative levels of mRNAs using the $2^{-\Delta \Delta C t}$ method and GAPDH was considered as the internal control.

2.8. Immunoblot Analysis. The liver tissues or the HSCs were lysed in RIPA Buffer ( $1 \mathrm{mM}$ EDTA pH 8.0, $50 \mathrm{mM}$ Tris- $\mathrm{HCl} \mathrm{pH} 8.0,2 \% \mathrm{SDS}$, and $5 \mathrm{mM} \mathrm{DTT}$ ), and their protein concentration was decided by the BCA assay (Beyotime Inc., Shanghai, China). The total protein (about $30 \mu \mathrm{g}$ ) was separated by a SDS-PAGE gel and transferred to PVDF (polyvinylidene fluoride) membranes (Invitrogen, CA, USA $)=$ and blocked with 5\% nonfat dry milk in PBST (phosphate-buffered saline with Tween), pH7.5. The membranes were immunoblotted with primary antibodies for 4 hours or overnight at $4^{\circ} \mathrm{C}$. The primary antibodies were all purchased from Cell Signaling Technology (MA, USA), and they were diluted at 1:1000 in the immunoblot analysis. Secondary antibodies with horseradish peroxidase were used in this study. The protein bands were determined by an enhanced chemiluminescence kit (Pierce, Rockford, USA). The corresponding semiquantitative analysis was based on optical density with ImageJ software.

2.9. Determination of the Apoptotic Cells by TUNEL. We determined the apoptosis of HSCs using TUNEL methods as previously described [19]. Briefly, the TUNEL and DAPI, which were from Sigma (Shanghai, China), were used to detect the apoptosis of cultured cells and the apoptotic cells could be TUNEL-positive. Then, the TUNEL-positive HSCs were calculated under a Carl Zeiss microscope (Axio Observer A1, Jena, Germany).

2.10. Statistical Analysis. Data were shown as the mean \pm SEM. Student's $t$-test was performed for comparisons between two groups, and one-way ANOVA test was employed for comparisons among several groups. Log-rank test was used for survival data. $P$ value $<0.05$ was considered to be statistically significant.

\section{Results}

3.1. Sophocarpine Increases the Survival Rate and Attenuates the LPS-Induced Liver Injury. The data in our study suggested that the 16-day survival rate was $73.3 \%$ (22 out of 30 ) and $76.7 \%$ (22 out of 30) in sophocarpine-pretreated group in a dose-dependent manner; meanwhile, the 16-day survival rate was $30.0 \%$ (9 out of 30 ) in the sepsis group (Figure 1(a)). Compared to the sepsis group, the 16-day survival rate was higher in the sophocarpine-treated group $(P<0.001)$; in the sham group (30 mice), the survival rate was $100 \%$ on the 16 th day. In a word, pretreatment of mice with sophocarpine before LPS injection remarkably decreased lethality in contrast to LPS-caused sepsis animals.

It has been reported that LPS-induced liver dysfunction may be assessed by serum liver-specific enzymes including AST, ALT, and ALP, and the morphological alterations of the liver may be observed by $H \& E$ staining. Firstly, we found that sophocarpine $(30 \mathrm{mg} / \mathrm{kg}$ and $60 \mathrm{mg} / \mathrm{kg}$ per day) recovered destructive damage of hepatocytes significantly in LPS-induced septic liver injury (Figures 1(b) and $1(\mathrm{c})$ ). Then, AST, ALT, and ALP levels in sepsis mice were higher than sham (normal) group, and sophocarpine significantly decreased AST, ALT, and ALP levels in the serum and liver of sepsis mice (Figures 2(a)-2(f)). Combined with the survival rate in Figure 1(a), the data revealed that sophocarpine showed its protective role in sepsis and sepsis-related acute liver injury via downregulating ALT, AST, and ALP expression.

3.2. Sophocarpine Ameliorates Oxidative Stress-Associated Indicators in LPS-Induced Mice. To demonstrate the effects of sophocarpine on oxidative stress in the liver of LPS-induced mice, we analyzed the antioxidative factors such as SOD, GSH, and CAT and detected the levels of $\mathrm{H}_{2} \mathrm{O}_{2}, \mathrm{O}_{2}^{--}$, and $\mathrm{NO}$ in the liver. The results showed that activity of SOD, 


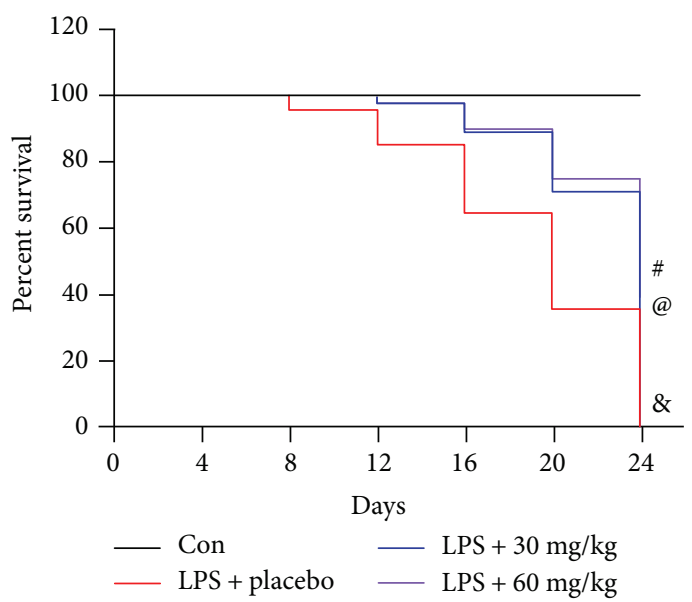

(a)

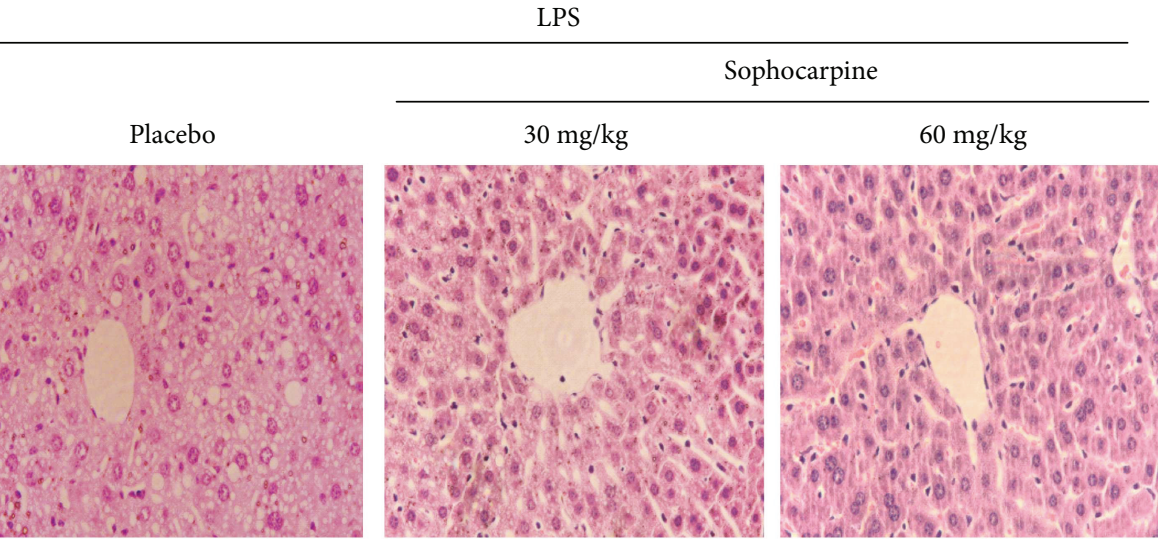

(b)

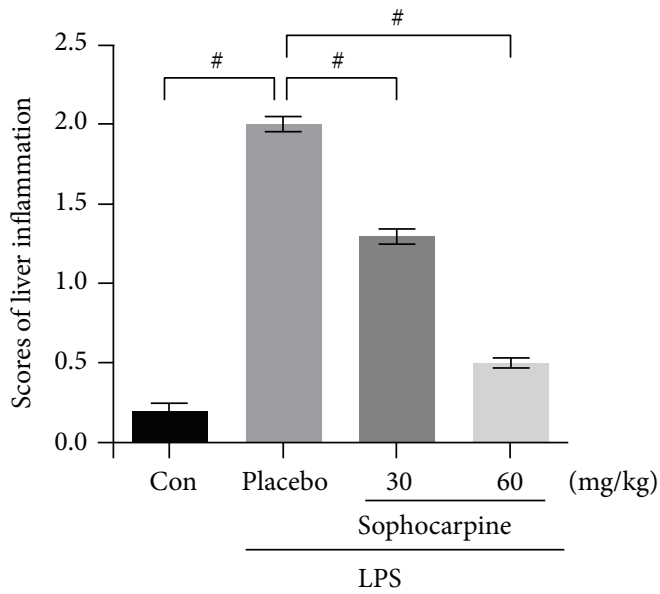

(c)

FIGURE 1: Sophocarpine ameliorates LPS-induced liver injury of mice. (a) Sophocarpine increased survival of endotoxemic mice induced by LPS; ${ }^{\#} P<0.001$, the sophocarpine-treated group $\left(30 \mathrm{mg} / \mathrm{kg}\right.$ body weight per day) versus the LPS-induced group; ${ }^{\circledR} P<0.001$, the sophocarpine-treated group $\left(30 \mathrm{mg} / \mathrm{kg}\right.$ body weight per day) versus the LPS-induced group; ${ }^{*} P<0.001$, the LPS-induced group $(5 \mathrm{mg} / \mathrm{kg}$ body weight) versus the normal group. (b) Liver sections stained with H\&E at a magnification of 200x. (c) Assessment of liver injury following portal inflammation scores; data are expressed as mean \pm SEM, $n=30$. ${ }^{\#} P<0.001$.

CAT, and GSH was decreased obviously in sepsis mice. As expected, sophocarpine (30 and $60 \mathrm{mg} / \mathrm{kg}$ ) evidently restored CAT activity (Figure 2(g)), GSH activity (Figure 2(h)), and SOD activity (Figure 2(i)). Moreover, hepatic $\mathrm{H}_{2} \mathrm{O}_{2}, \mathrm{O}_{2}^{\cdot-}$, and NO levels were determined in mice. The results indicated that LPS elevated the $\mathrm{H}_{2} \mathrm{O}_{2}, \mathrm{O}_{2}^{--}$, and $\mathrm{NO}$ levels in the liver of mice, and sophocarpine significantly may suppress the $\mathrm{H}_{2} \mathrm{O}_{2}, \mathrm{O}_{2}^{--}$, and $\mathrm{NO}$ production in the liver of LPS- 


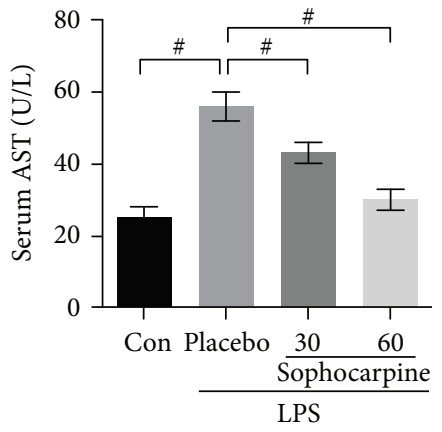

(a)

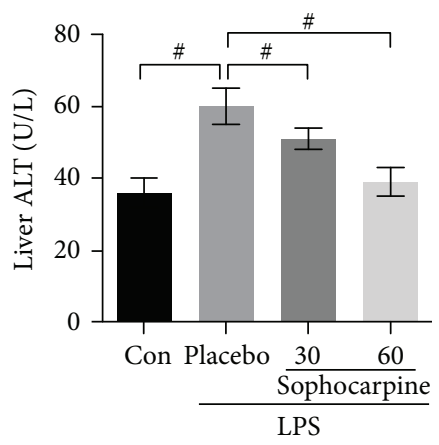

(d)

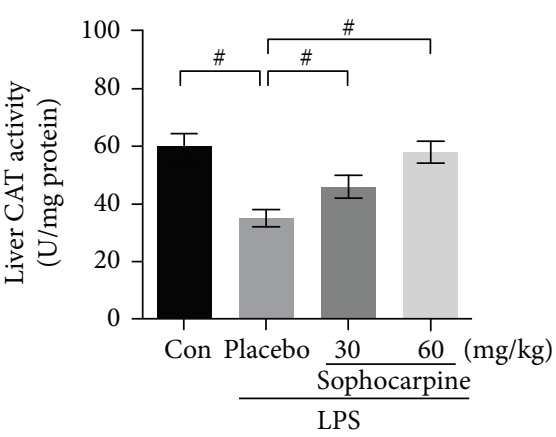

(g)

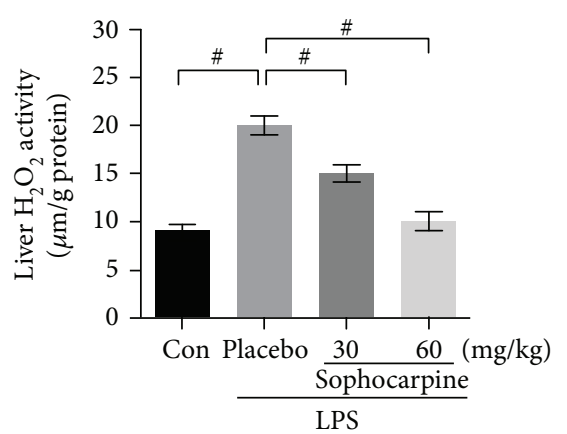

(j)

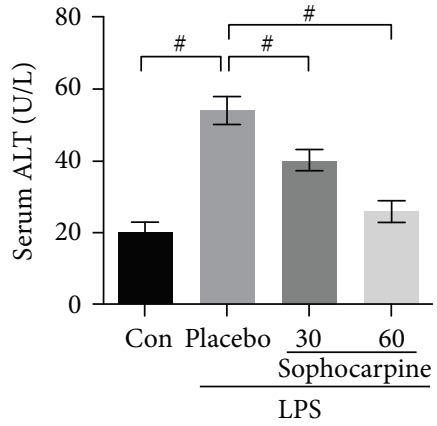

(b)

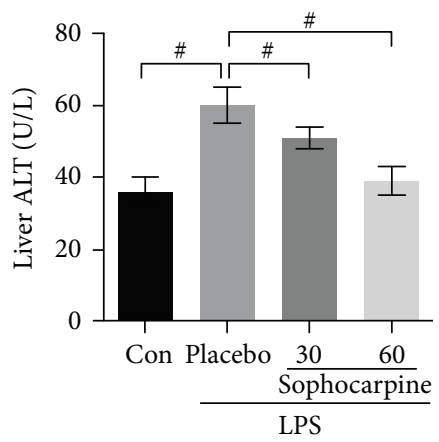

(e)

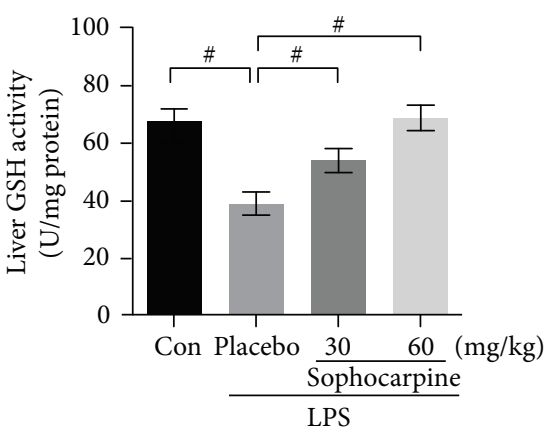

(h)

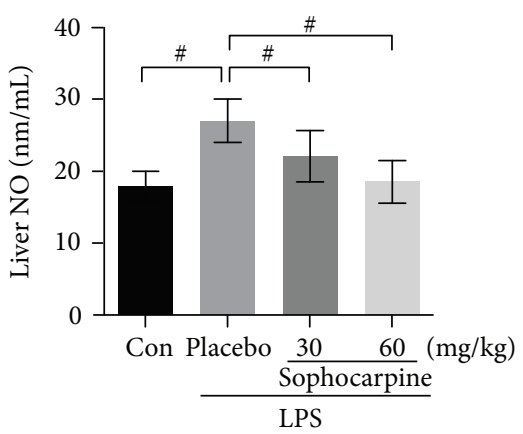

(k)

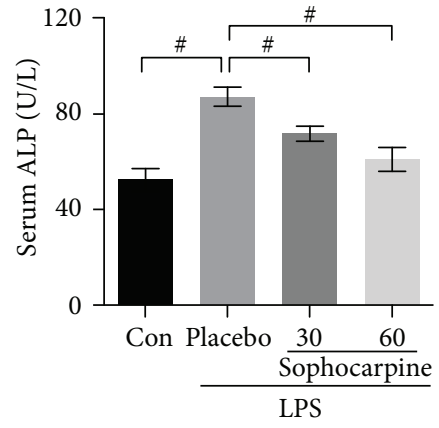

(c)

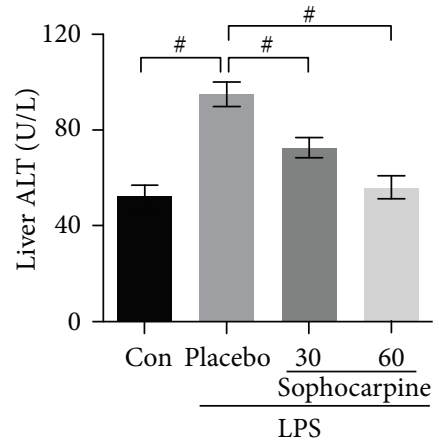

(f)

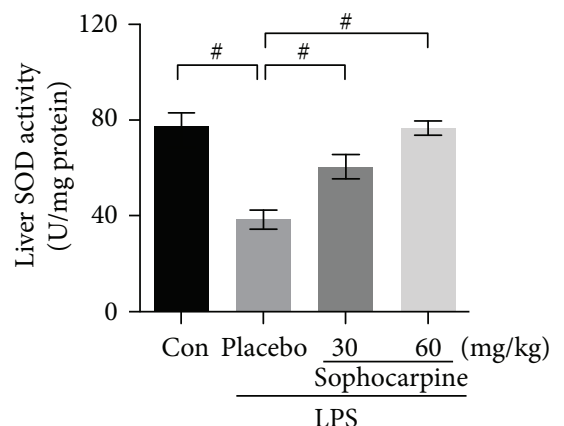

(i)

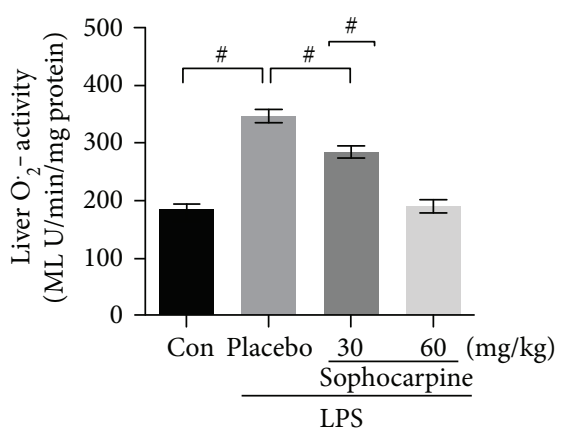

(l)

FIGURE 2: Sophocarpine reduces production of liver injury-related factors and improves oxidative stress in the liver of LPS-induced mice. $(\mathrm{a}-\mathrm{c})$ Sophocarpine decreased concentrations of AST, ALT, and ALP in serum determined by ELISA. (d-f) Sophocarpine downregulated levels of AST, ALT, and ALP in the liver analyzed by ELISA. The levels of CAT (g), GSH (h), SOD (i), $\mathrm{H}_{2} \mathrm{O}_{2}(\mathrm{j})$, NO $(\mathrm{k})$, and $\mathrm{O}_{2}^{--}$(l) determined by ELISA. Data are expressed as mean $\pm \mathrm{SEM}, n=30 .{ }^{\#} P<0.001$.

administrated mice (Figures 2(j)-2(l)). Thus, sophocarpine prevented liver injury via attenuating ROS production and oxidative stress in LPS-induced mice.
3.3. The Effects of Sophocarpine on ROS Pathway in LPSInduced Mice. To investigate the inhibitory mechanism of sophocarpine against oxidative stress, we examined the 


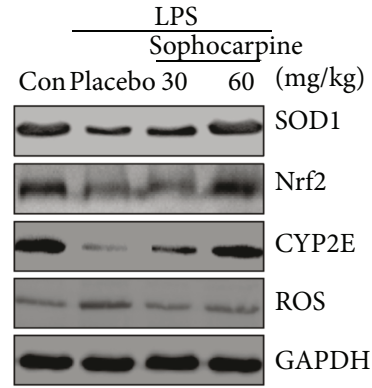

(a)

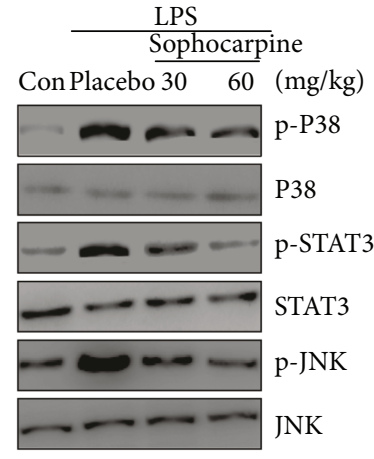

(c)

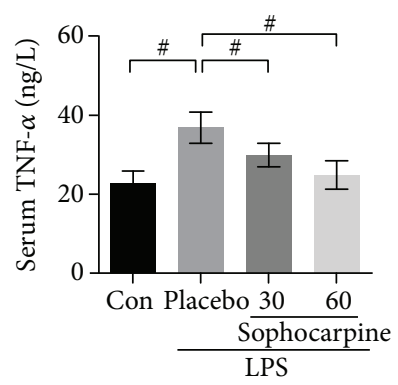

(e)

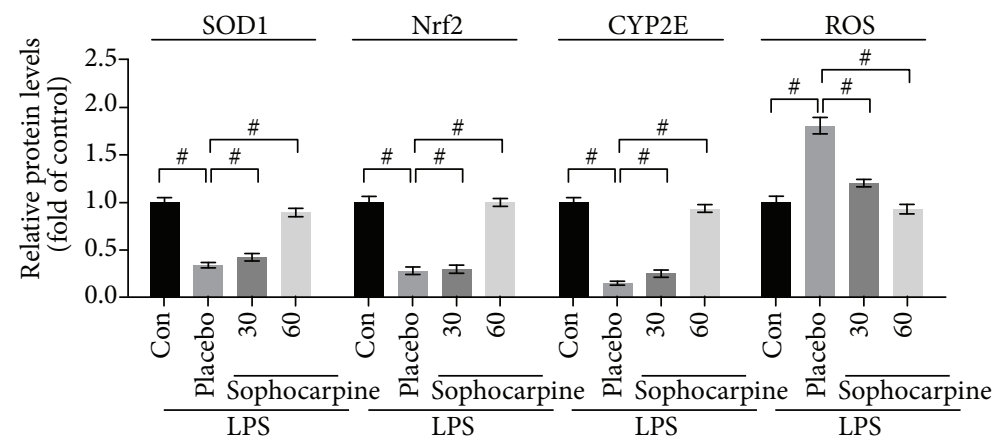

(b)

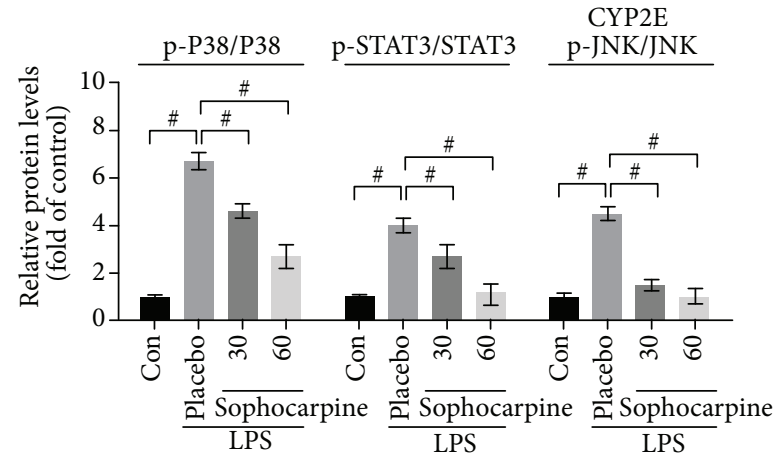

(d)

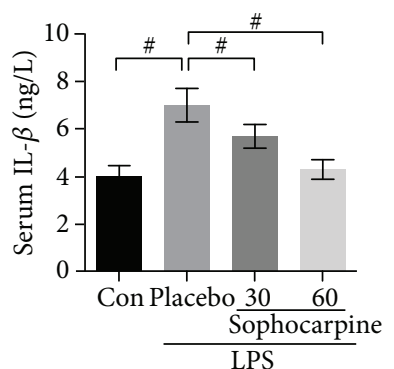

(f)

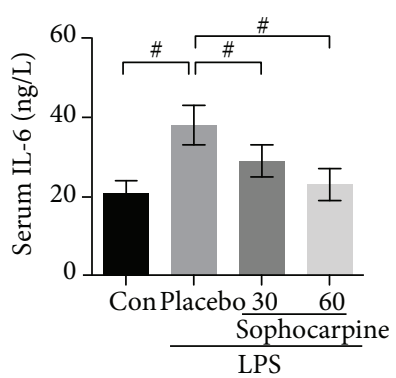

(g)

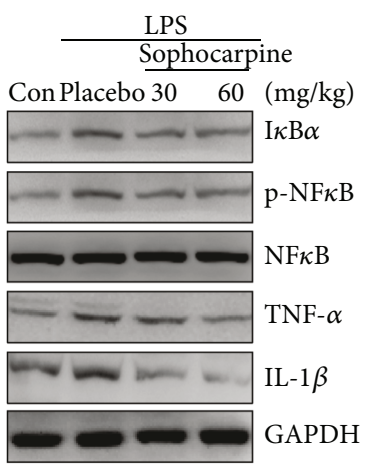

(h)

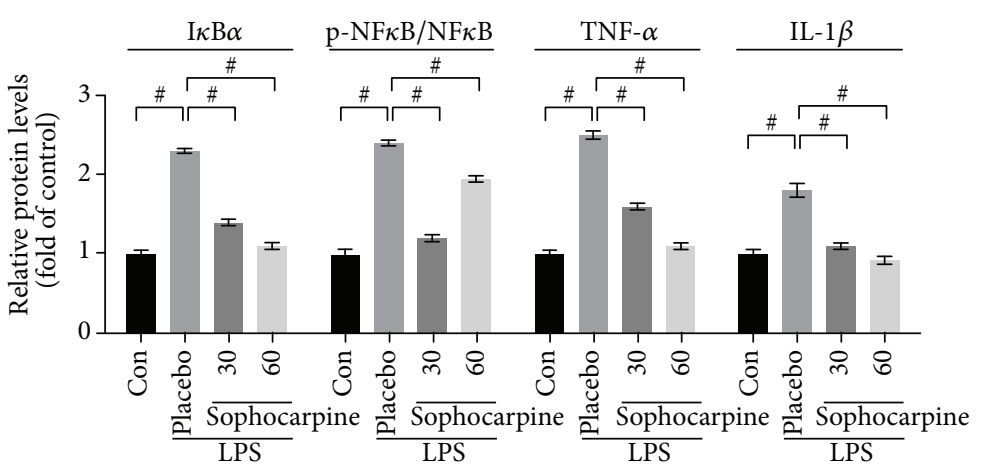

(i)

FIGURE 3: Effect of Sophocarpine on the expression of the hepatic oxidative stress-associated protein and inflammatory signaling pathway in the liver of LPS-induced mice. ( $a$ and b) Sophocarpine upregulated the expression of SOD1, Nrf2, and CYPE2 and downregulated the levels of ROS protein detected by Western blot (a) and the semiquantitative analysis of lanes was based on optical density with ImageJ software (b); data are expressed as mean \pm SEM, ${ }^{\#} P<0.001$. (c and d) Sophocarpine inhibited phosphorylation of P38, STAT3, and JNK and (c) and the corresponding semiquantitative analysis was based on optical density with ImageJ software (d). (e-g) Serum levels of TNF- $\alpha$, IL- $1 \beta$, and IL-6 analyzed by ELISA in mice; data are expressed as mean $\pm \mathrm{SEM},{ }^{\#} P<0.001$. (h and i) Sophocarpine blocked the expression of $\mathrm{I} \kappa \mathrm{B} \alpha$ and inactivated the NF- $\kappa \mathrm{B}$; also, sophocarpine suppressed the expression of TNF- $\alpha$ and IL-1 $\beta$ demonstrated by Western blot (h). The semiquantitative analysis of lanes was based on optical density with ImageJ software (i); data are expressed as mean \pm SEM, ${ }^{\#} P<0.001$. 


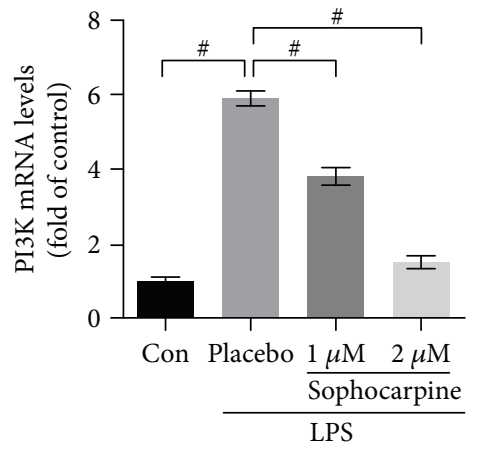

(a)

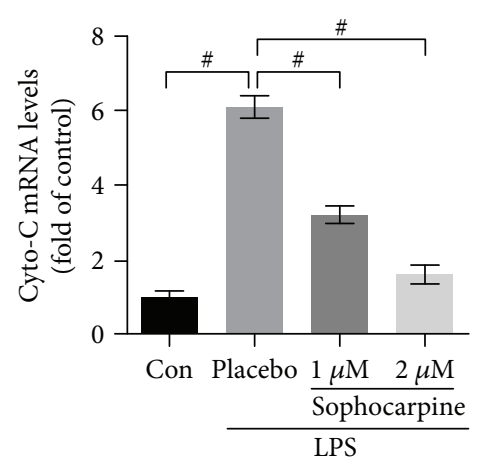

(c)

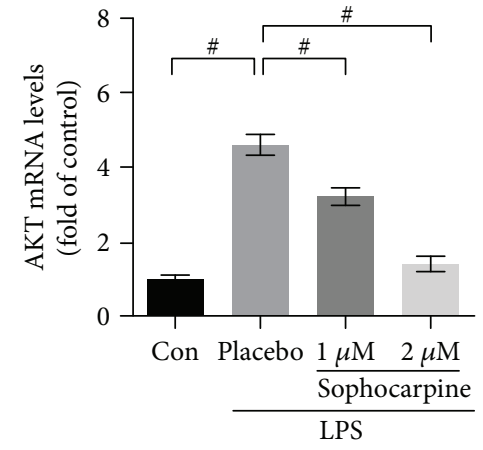

(b)

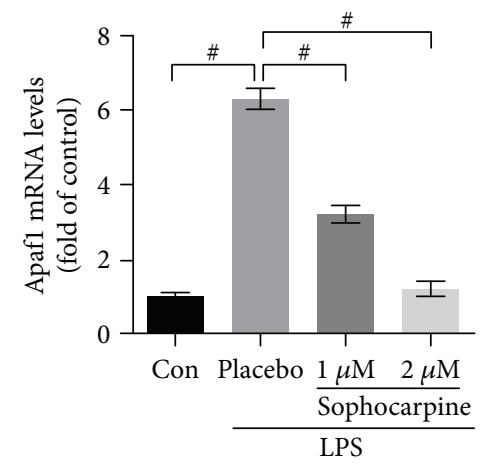

(d)

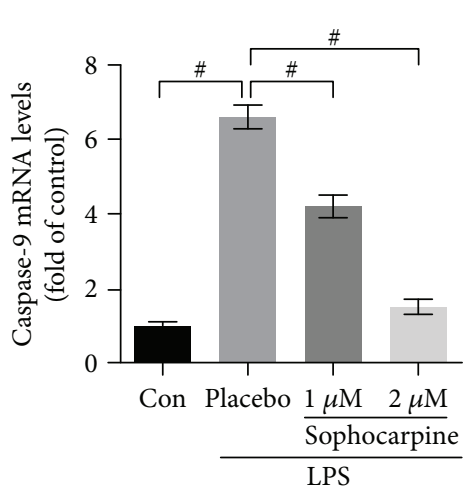

(e)

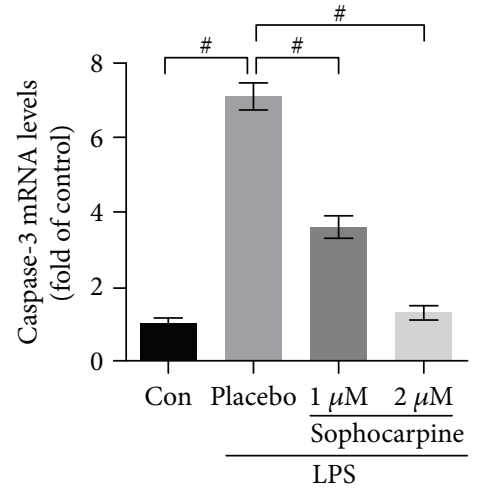

(f)

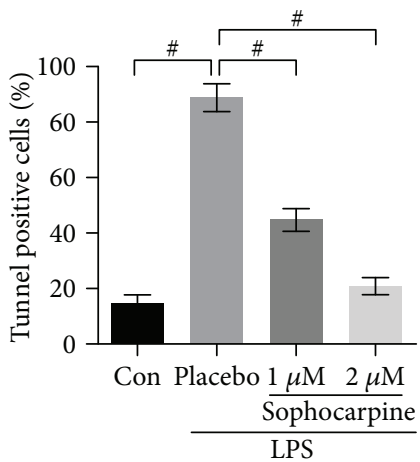

(g)

FIgURE 4: Sophocarpine improves injury of LPS-treated hepatic stellate cells (HSCs) by suppressing apoptosis. (a-f) Sophocarpine decreased the mRNA expression of PI3K, AKT, Cyto-C, Apaf1, caspase-9, and caspase-3 analyzed by real-time PCR; the data are expressed as mean \pm SEM, ${ }^{\#} P<0.001$. (g) Evaluation of apoptosis in HSCs by TUNEL assays and number of TUNEL-positive cells was calculated under a microscope; the data are expressed as mean $\pm \mathrm{SEM},{ }^{\#} P<0.001$.

ROS signaling in the LPS-induced liver of mice by Western blot. As shown in Figure 3, the results demonstrated that SOD1 and Nrf2 expression was dramatically downregulated in the LPS-induced liver, compared with the normal mice. After injection of sophocarpine, data presented that the levels of SOD1 and Nrf2 were elevated markedly by sophocarpine in a dose-dependent manner in endotoxic mice (Figures 3(a) and 3(b)). Moreover, we investigated oxidative stress-associated protein including ROS, CYP2E, P38, JNK, and STAT3 in mice. The data showed that ROS, CYP2E, P38, STAT3, and JNK were increased in LPSinduced mice (Figures 3(c) and 3(d)). However, the expression of CYP2E and ROS, as well as the phosphorylation of
P38, STAT3, and JNK, was significantly inhibited by sophocarpine in a dose-dependent manner (Figures 3(c) and $3(\mathrm{~d})$ ). Thus, sophocarpine protected against endotoxemia via improving ROS-mediated oxidative stress in the liver of sepsis model animals.

3.4. Sophocarpine Attenuates Inflammation in LPS-Induced Liver Injury. As shown in Figures 3(e)-3(g), the LPSinduced mice exhibited higher content of serum IL- $1 \beta$, TNF- $\alpha$, and IL- 6 compared with the normal mice. Compared with the LPS-induced group, sophocarpine administration (30 $\mathrm{mg} / \mathrm{kg}$ and $60 \mathrm{mg} / \mathrm{kg}$ per day) significantly reduced serum levels of TNF- $\alpha$, IL-1 $\beta$, and IL- 6 in LPS-induced mice. 


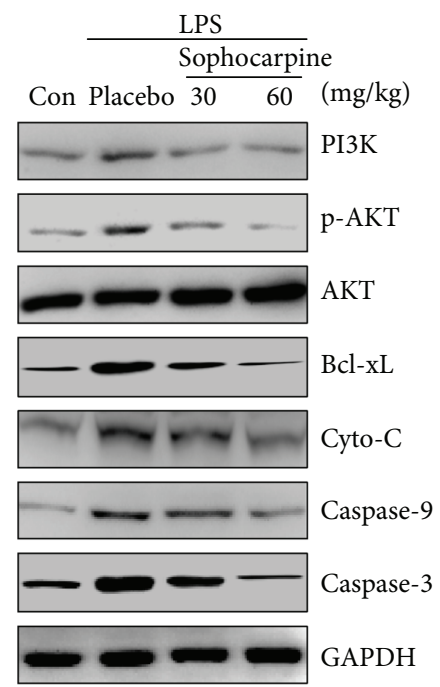

(a)

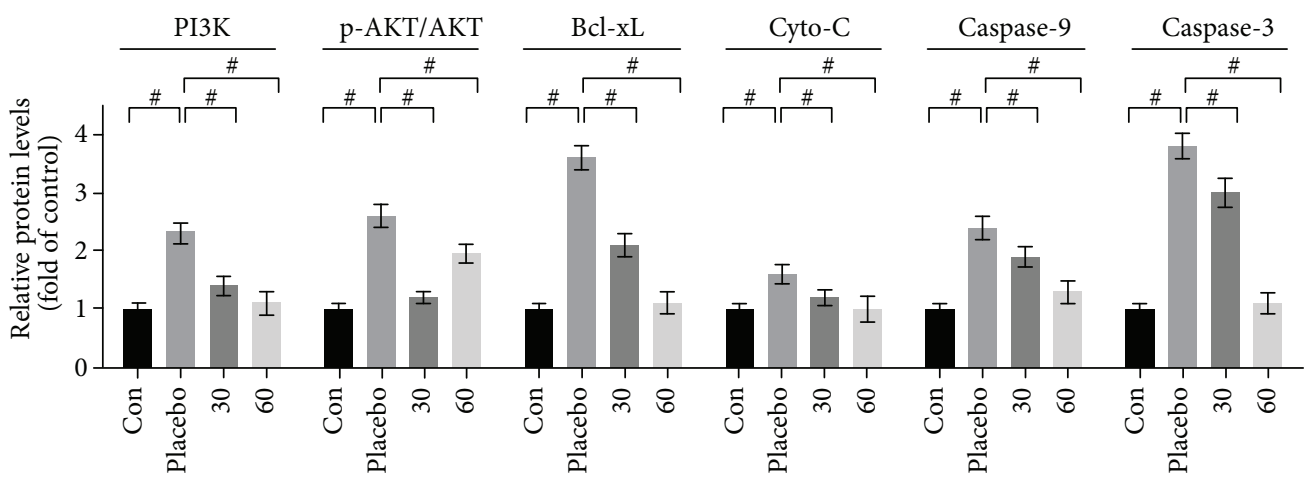

(b)

FIGURE 5: Sophocarpine represses apoptosis-associated signaling protein in the liver of LPS-induced mice. (a) Sophocarpine decreased the expression of PI3K, Bcl-xL, Cyto-C, caspase-9, and caspase-3 and depressed phosphorylation of AKT determined by Western blot. (b) The semiquantitative analysis of lanes was based on optical density with ImageJ software; data are expressed as mean \pm SEM, ${ }^{\#} P<0.001$.

Similarly, we found that LPS enhanced the protein expression of TNF- $\alpha$ and IL- $1 \beta$, and LPS also upregulated expression of $\mathrm{I} \kappa \mathrm{B} \alpha$ protein and phosphorylation of NF- $\kappa \mathrm{B}$ (Figures 3(h) and 3(i)). Contrarily, sophocarpine downregulated the expression of the above proteins in inflammation of the LPS-induced liver of mice (Figures 3(h) and 3(i)). The data indicated that sophocarpine may ameliorate LPSinduced liver injury by suppressing inflammation responses.

3.5. Sophocarpine Suppresses Apoptosis in Liver of LPSInduced Mice. To explore the effects of sophocarpine on apoptosis, we analyzed the PI3K/AKT pathway-related apoptosis progressing. The data proved that LPS significantly promoted the expression of PI3K and AKT, which were restored to the normal levels by administration of sophocarpine at $60 \mathrm{mg} / \mathrm{kg}$ per day. Furthermore, apoptosis-associated proteins were analyzed by Western blot in this section. Then, we found that Bcl-xL, Cyto-c, Apaf1, and cleaved caspase- 9 and caspase3 were increased by LPS dramatically (Figures 4(a) and 4(b)), indicating that LPS may promote apoptosis development in the liver of mice. After administrating sophocarpine, LPSinduced apoptosis in the liver may be significantly inhibited by depressing the expression of the related proteins above (Figures 5(a) and 5(b)).

To verify the vital role of apoptosis in the progression of LPS-induced acute liver injury, we analyzed the mRNA expression of the apoptosis-associated genes above by realtime PCR. The results showed that sophocarpine markedly downregulated the mRNA levels of PI3K and AKT (Figures 6(a) and 6(b)), and sophocarpine also reduced the mRNA levels of Bad, Bax-xL, Cyto-c, Apaf1, caspase-9, caspase-3, and caspase- 6 in the liver of LPS-caused liver failure (Figures 6(c)-6(i)). Thus, sophocarpine attenuated liver injury by repressing the expression of apoptosis-related genes at both mRNA and protein levels.

3.6. Sophocarpine Improves Injury of LPS-Treated HSCs by Suppressing Apoptosis. To study the potential role of sophocarpine on LPS-stimulated hepatic stellate cells (HSCs), we pretreated HSCs with LPS. Then, the LPS-stimulated HSCs were subjected to sophocarpine incubation in order to determine whether sophocarpine may improve the liver injury by regulating apoptosis. In the present study, we found that LPS significantly elevated apoptosis-related gene 


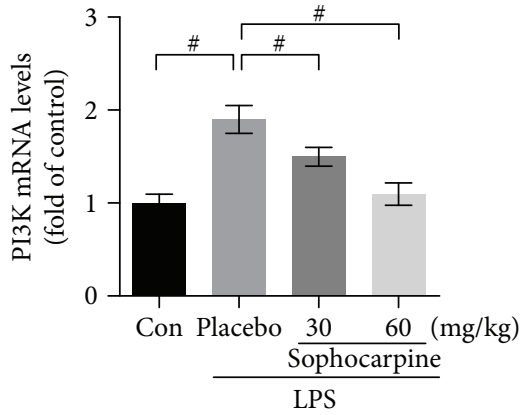

(a)

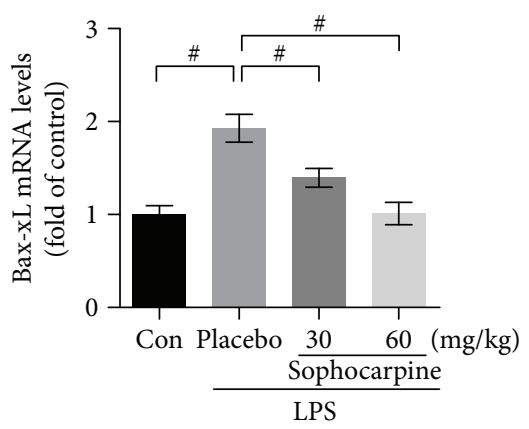

(d)

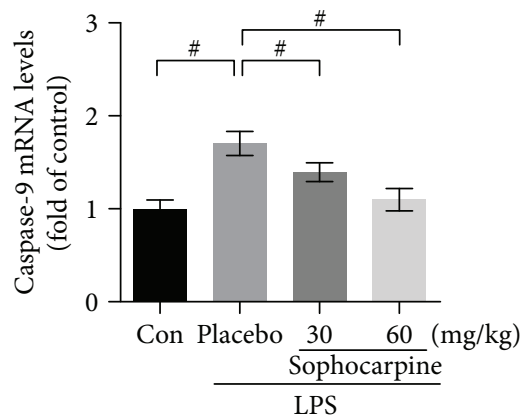

(g)

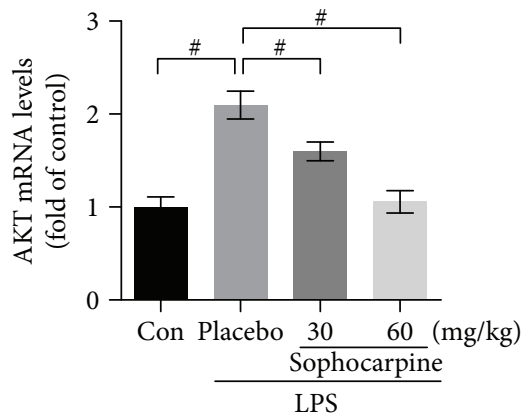

(b)

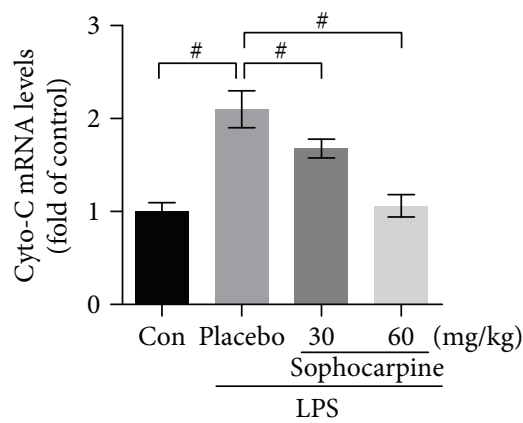

(e)

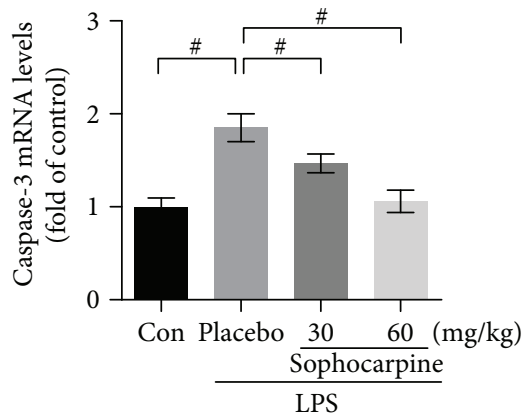

(h)

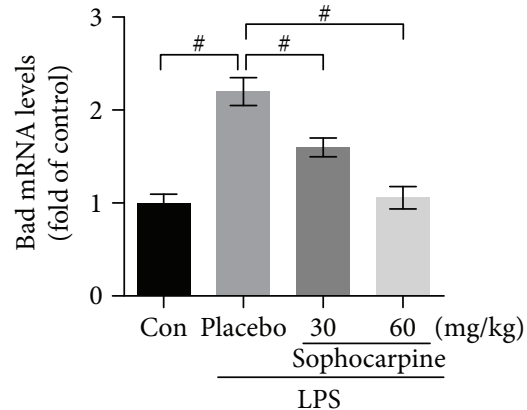

(c)

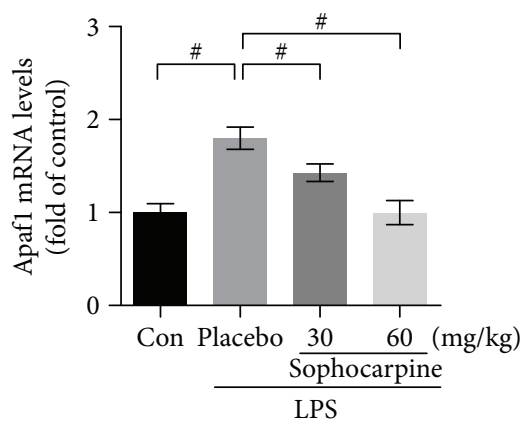

(f)

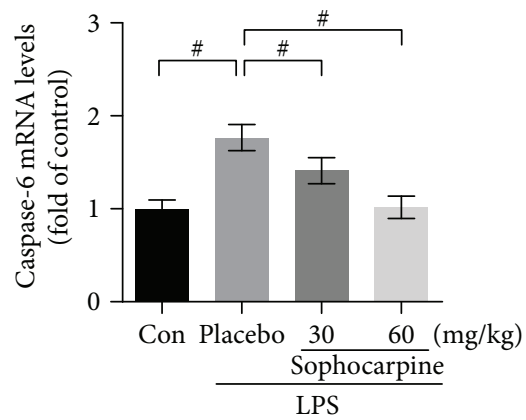

(i)

FIGURE 6: Sophocarpine suppresses apoptosis-associated gene mRNA levels in the liver of LPS-induced mice. Sophocarpine decreased the mRNA expression of PI3K (a), AKT (b), Bad (c), Bcl-xL (d), Cyto-C (e), Apaf1 (f), caspase-9 (g), caspase-3 (h), and caspase-6 (i) analyzed by real-time PCR. The data are expressed as mean \pm SEM, ${ }^{\#} P<0.001$.

expression, including PI3K and AKT, as well as Cyto-C, Apaf1, caspase-9, and caspase-3 (Figures 4(a)-4(f)). However, sophocarpine obviously inhibited this gene expression (Figures 4(a)-4(f)). Subsequently, sophocarpine may attenuate HSC damage and apoptosis in a dose-dependent manner (Figure $4(\mathrm{~g})$ ). These in vitro data suggested that sophocarpine could improve HSCs injury by suppressing PI3K/AKTassociated apoptosis.

\section{Discussion}

Nowadays, the mechanism of acute liver injury (or failure) still has not been completely investigated and required further study for promising clinical strategies [28]. Researches proposed LPS-induced acute liver injury, possibly derived from endotoxemia, was related to the inflammatory-associated Kupffer cells as well as inflammatory mediators including
TNF- $\alpha$, IL- $1 \beta$, nitric oxide, and superoxide [29]. Furthermore, LPS extends acute liver injury by modulating the oxidative stress and production of free radical, protein synthesis, and apoptosis of hepatocytes [30]. In this study, we found that ALT, AST, and ALP were upregulated in the serum and liver of LPS-induced mice and these three indicators above were dramatically downregulated by sophocarpine (Figures $2(a)-2(f)$ ).

Oxidative stress that is associated with cellular metabolism in the $\mathrm{O}_{2}$ environment has been regarded as a balance between prooxidant and antioxidant [31]. Based on the cellular microenvironment, the prooxidation process generates ROS including hydrogen peroxide $\left(\mathrm{H}_{2} \mathrm{O}_{2}\right)$ and superoxide radical $\left(\mathrm{O}_{2}^{--}\right)$[32]. The prooxidants $\mathrm{H}_{2} \mathrm{O}_{2}, \mathrm{O}_{2}^{--}$, and $\mathrm{NO}$ are the main sources of ROS production according to the diverse stress conditions $[33,34]$. Previous studies have demonstrated that the ROS plays a vital role in septic shock and organ failure [35]. Also, excessive ROS is expressed in LPS- 
induced liver injury and antioxidant agents seem to be a good choice to reverse the liver injury [35]. As a main antioxidant and $\mathrm{O}_{2}^{--}$scavenger, SOD may react with ROS and NO [36]. CAT may reduce ROS production by degrading $\mathrm{H}_{2} \mathrm{O}_{2}$ into oxygen and water [37]. Additionally, GSH can protect the liver and other organs against oxidative stress by decreasing the levels of $\mathrm{H}_{2} \mathrm{O}_{2}$ and lipid hydroperoxide [38]. In the current study, we found that LPS significantly elevated the levels of $\mathrm{H}_{2} \mathrm{O}_{2}, \mathrm{O}_{2}^{--}$, and $\mathrm{NO}$, which were downregulated nearly to normal levels by sophocarpine in a dose-dependent manner. Meanwhile, sophocarpine obviously upregulated the activity and expression of endogenous antioxidants, such as SOD, CAT, and GSH, suggesting that sophocarpine shows its potential antioxidative by blocking ROS-mediated signaling. As an essential sensor of redox status in ROS process, cellular Nrf2 often binds to the cytoskeletal-anchoring protein under normal conditions [39]. As the main contributor, CYP2E always promotes the production of ROS in liver injury and ethanol-induced oxidative stress [11]. In the present study, LPS decreased the levels of CYP2E, Nrf2, and ROS, which may be restored to normal by sophocarpine administration, indicating that sophocarpine possesses the activity to attenuate oxidative stress resulting in the improvement of LPStriggered acute liver injury.

It has been reported that PI3K/Akt signaling plays vital roles in survival and antiapoptosis of cells by modulating its downstream targets, including caspase-9, caspase-3, and Bad [14, 34, 36]. Meanwhile, NF- $\kappa \mathrm{B}$ signaling has been demonstrated to be an important regulator in apoptosis of cancer cells $[34,36]$. However, it remains unknown about the role of PI3K/Akt signaling in the liver of LPS-induced mice. In this study, sophocarpine significantly downregulated the expression of $\mathrm{PI} 3 \mathrm{~K}$ and phosphorylation of AKT, implying that the chemical can inhibit the expression of activated AKT. Furthermore, we found that sophocarpine reduced the expression of $\mathrm{Bcl}-\mathrm{xL}$, which was an antiapoptotic gene. Sophocarpine downregulated the expression of cleaved caspases substantially. Consequently, the data indicate that sophocarpine suppresses the activation of $\mathrm{PI} 3 \mathrm{~K} / \mathrm{AKT}$ signaling resulting in apoptosis of liver injury induced by LPS.

$N F-\kappa B$ signaling is a central regulator of inflammatory cytokines, such as TNF- $\alpha$ and IL- $1 \beta$, which are key factors in inflammation responses [40]. In the current study, we found that LPS dramatically upregulated content and activity of TNF- $\alpha$, IL- $1 \beta$, and IL- 6 in the serum and liver of mice. Thus, LPS-induced liver failure may be generated by promoting the inflammation responses including the mentioned inflammatory signaling and cytokines, which can be inhibited by sophocarpine in a dose-dependent manner.

In conclusion, sophocarpine shows the activity against oxidative stress and inflammation in the LPS-induced liver injury of mice. Moreover, sophocarpine suppresses the liver injury in LPS-induced mice with endotoxemia through blocking the inflammatory pathway NF- $\kappa \mathrm{B}$, contributing to downregulation of proinflammatory cytokines. Meanwhile, sophocarpine affects apoptosis in the liver by inhibiting the PI3K/AKT-associated signaling. These findings suggest sophocarpine might be a novel and promising agent to improve inflammation, apoptosis, and oxidative responses in the liver of mice with endotoxemia.

\section{Conflicts of Interest}

The authors declare no conflicts of interests.

\section{Authors' Contributions}

Zhengyu Jiang and Yan Meng performed the majority of the experiments and contributed to manuscript preparation. Xiaoming Deng and Jinjun Bian designed the whole article and manuscript preparation. Changli Wang and Lulong Bo contributed part of the experiments and analysis of statistics.

\section{Acknowledgments}

The authors are very grateful for the members in their laboratory especially Dr. Tianxin Chen and Dr. Lili Chen of the School of Life Science, Nanjing University for their technical support, and Dr. Mengda Xu for his encouraging discussion and suggestion for the manuscript. Work in the authors' laboratories is supported by the National Natural Science Foundation of China (Grant nos. 81671939, 81671887,81471845 , and 81772105) and Scientific Research Program of Shanghai Science and Technology Committee (Grant no. 15411963200).

\section{References}

[1] J. M. Canabal and D. J. Kramer, "Management of sepsis in patients with liver failure," Current Opinion in Critical Care, vol. 14, no. 2, pp. 189-197, 2008.

[2] J. Yan, S. Li, and S. Li, "The role of the liver in sepsis," International Reviews of Immunology, vol. 33, no. 6, pp. 498-510, 2014.

[3] T. van der Poll, "Future of sepsis therapies," Critical Care, vol. 20, no. 1, p. 106, 2016.

[4] D. M. Boé, T. R. Richens, S. A. Horstmann et al., "Acute and chronic alcohol exposure impair the phagocytosis of apoptotic cells and enhance the pulmonary inflammatory response," Alcoholism, Clinical \& Experimental Research, vol. 34, no. 10, pp. 1723-1732, 2010.

[5] Z. Zhang, G. J. Bagby, D. Stoltz, P. Oliver, P. O. Schwarzenberger, and J. K. Kolls, "Prolonged ethanol treatment enhances lipopolysaccharide/phorbol myristate acetate-induced tumor necrosis factor- $\alpha$ production in human monocytic cells," Alcoholism, Clinical \& Experimental Research, vol. 25, no. 3, pp. 444-449, 2001.

[6] W. Bernal, "Acute liver failure: review and update," International Anesthesiology Clinics, vol. 55, no. 2, pp. 92-106, 2017.

[7] Y. Hattori, K. Hattori, T. Suzuki, and N. Matsuda, "Recent advances in the pathophysiology and molecular basis of sepsis-associated organ dysfunction: novel therapeutic implications and challenges," Pharmacology \& Therapeutics, vol. 177, pp. 56-66, 2017.

[8] V. M. Victor, M. Rocha, J. V. Esplugues, and M. De la Fuente, "Role of free radicals in sepsis: antioxidant therapy," Current Pharmaceutical Design, vol. 11, no. 24, pp. 3141-3158, 2005. 
[9] M. Andrades, C. Ritter, M. R. de Oliveira, E. L. Streck, J. C. Fonseca Moreira, and F. Dal-Pizzol, "Antioxidant treatment reverses organ failure in rat model of sepsis: role of antioxidant enzymes imbalance, neutrophil infiltration, and oxidative stress," The Journal of Surgical Research, vol. 167, no. 2, pp. E307-E313, 2011.

[10] A. J. Hayes and D. J. Mole, "Mitogen-activated protein kinase/ extracellular signal-regulated kinase kinase inhibition during sepsis dampens the early systemic inflammatory response," Critical Care Medicine, vol. 44, no. 8, pp. 1628-1629, 2016.

[11] N. N. Rahbari, A. Mehrabi, N. M. Mollberg et al., "Hepatocellular carcinoma current management and perspectives for the future," Annals of Surgery, vol. 253, no. 3, pp. 453-469, 2011.

[12] A. Bujold and L. A. Dawson, "Stereotactic radiation therapy and selective internal radiation therapy for hepatocellular carcinoma," Cancer/Radiothérapie, vol. 15, no. 1, pp. 54-63, 2011.

[13] C. Ritter, M. E. Andrades, A. Reinke, S. Menna-Barreto, J. C. F. Moreira, and F. Dal-Pizzol, "Treatment with $N$-acetylcysteine plus deferoxamine protects rats against oxidative stress and improves survival in sepsis," Critical Care Medicine, vol. 32, no. 2, pp. 342-349, 2004.

[14] B. Raynard, A. Balian, D. Fallik et al., "Risk factors of fibrosis in alcohol-induced liver disease," Hepatology, vol. 35, no. 3, pp. 635-638, 2002.

[15] P. Mandrekar, S. Bala, D. Catalano, K. Kodys, and G. Szabo, "The opposite effects of acute and chronic alcohol on lipopolysaccharide-induced inflammation are linked to IRAK-M in human monocytes," The Journal of Immunology, vol. 183, no. 2, pp. 1320-1327, 2009.

[16] H. Zhou, M. Yu, K. Fukuda et al., "IRAK-M mediates Toll-like receptor/IL-1R-induced $\mathrm{NF} \kappa \mathrm{B}$ activation and cytokine production," The EMBO Journal, vol. 32, no. 4, pp. 583-596, 2013.

[17] B. Venkatesan, A. J. Valente, S. D. Prabhu, P. Shanmugam, P. Delafontaine, and B. Chandrasekar, "EMMPRIN activates multiple transcription factors in cardiomyocytes, and induces interleukin-18 expression via Rac1-dependent PI3K/Akt/ IKK/NF- $\kappa \mathrm{B}$ and MKK7/JNK/AP-1 signaling," Journal of Molecular and Cellular Cardiology, vol. 49, no. 4, pp. 655663, 2010.

[18] R. G. Baker, M. S. Hayden, and S. Ghosh, "NF- $\kappa$ B, inflammation, and metabolic disease," Cell Metabolism, vol. 13, no. 1, pp. 11-22, 2011.

[19] W. Zhong, K. Qian, J. Xiong, K. Ma, A. Wang, and Y. Zou, "Curcumin alleviates lipopolysaccharide induced sepsis and liver failure by suppression of oxidative stress-related inflammation via PI3K/AKT and NF- $\kappa \mathrm{B}$ related signaling," Biomedicine \& Pharmacotherapy, vol. 83, pp. 302-313, 2016.

[20] C. Dan, B. Jinjun, H. Zi-Chun et al., "Modulation of TNF- $\alpha$ mRNA stability by human antigen $\mathrm{R}$ and miR181s in sepsisinduced immunoparalysis," EMBO Molecular Medicine, vol. 7, no. 2, pp. 140-157, 2015.

[21] M. Papurica, A. F. Rogobete, D. Sandesc et al., "The expression of nuclear transcription factor kappa $\mathrm{B}(\mathrm{NF}-\kappa \mathrm{B})$ in the case of critically Ill polytrauma patients with sepsis and its interactions with microRNAs," Biochemical Genetics, vol. 54, no. 4, pp. 337-347, 2016.

[22] Y. Zhang, S. Wang, Y. Li, Z. Xiao, Z. Hu, and J. Zhang, "Sophocarpine and matrine inhibit the production of TNF- $\alpha$ and IL- 6 in murine macrophages and prevent cachexiarelated symptoms induced by colon 26 adenocarcinoma in mice," International Immunopharmacology, vol. 8, no. 13-14, pp. 1767-1772, 2008.
[23] Y. Gao, G. Li, C. Li et al., "Anti-nociceptive and antiinflammatory activity of sophocarpine," Journal of Ethnopharmacology, vol. 125, no. 2, pp. 324-329, 2009.

[24] B. Guo, C. Li, Z. Deng et al., "A new method for measurement of (-)-sophocarpine, a candidate therapeutic for viral myocarditis, in plasma: application to a toxicokinetic study in beagle dogs," Rapid Communications in Mass Spectrometry, vol. 19, no. 19, pp. 2840-2848, 2005.

[25] Y. Gao, W. Jiang, C. Dong et al., "Anti-inflammatory effects of sophocarpine in LPS-induced RAW 264.7 cells via NF- $\kappa$ B and MAPKs signaling pathways," Toxicology In Vitro, vol. 26, no. 1, pp. 1-6, 2012.

[26] E. Oztürk, S. Demirbilek, A. Köroğlu et al., "Propofol and erythropoietin antioxidant properties in rat brain injured tissue," Progress in Neuro-Psychopharmacology and Biological Psychiatry, vol. 32, no. 1, pp. 81-86, 2008.

[27] S. Guo, Y. Zhang, Z. Wang, Y. Yu, and G. Wang, "Intraperitoneal gardiquimod protects against hepatotoxicity through inhibition of oxidative stress and inflammation in mice with sepsis," Journal of Biochemical and Molecular Toxicology, vol. 31, no. 8, article e21923, 2017.

[28] H. Jaeschke, "Reactive oxygen and mechanisms of inflammatory liver injury: present concepts," Journal of Gastroenterology and Hepatology, vol. 26, pp. 173-179, 2011.

[29] C. M. Raval, J. L. Zhong, S. A. Mitchell, and R. M. Tyrrell, "The role of Bach1 in ultraviolet A-mediated human heme oxygenase 1 regulation in human skin fibroblasts," Free Radical Biology \& Medicine, vol. 52, no. 1, pp. 227-236, 2012.

[30] R. Franco and J. A. Cidlowski, "Glutathione efflux and cell death," Antioxidants \& Redox Signaling, vol. 17, no. 12, pp. 1694-1713, 2012.

[31] V. Sanchez-Valle, N. C. Chavez-Tapia, M. Uribe, and N. Mendez-Sanchez, "Role of oxidative stress and molecular changes in liver fibrosis: a review," Current Medicinal Chemistry, vol. 19, no. 28, pp. 4850-4860, 2012.

[32] J. K. Kiecolt-Glaser, K. J. Preacher, R. C. MacCallum, C. Atkinson, W. B. Malarkey, and R. Glaser, "Chronic stress and age-related increases in the proinflammatory cytokine IL-6," Proceedings of the National Academy of Sciences of the United States of America, vol. 100, no. 15, pp. 9090-9095, 2003.

[33] I. B. Slimen, T. Najar, A. Ghram, H. Dabbebi, M. Ben Mrad, and M. Abdrabbah, "Reactive oxygen species, heat stress and oxidative-induced mitochondrial damage. A review," International Journal of Hyperthermia, vol. 30, no. 7, pp. 513-523, 2014.

[34] Y. Funato, T. Michiue, M. Asashima, and H. Miki, "The thioredoxin-related redox-regulating protein nucleoredoxin inhibits Wnt- $\beta$-catenin signalling through dishevelled," Nature Cell Biology, vol. 8, no. 5, pp. 501-508, 2006.

[35] P. H. Zapelini, G. T. Rezin, M. R. Cardoso et al., “Antioxidant treatment reverses mitochondrial dysfunction in a sepsis animal model," Mitochondrion, vol. 8, no. 3, pp. 211-218, 2008.

[36] Y. Ren, X. Yang, X. Niu, S. Liu, and G. Ren, "Chemical characterization of the avenanthramide-rich extract from oat and its effect on D-galactose-induced oxidative stress in mice," Journal of Agricultural and Food Chemistry, vol. 59, no. 1, pp. 206-211, 2011.

[37] S. Azarabadi, H. Abdollahi, M. Torabi, Z. Salehi, and J. Nasiri, "ROS generation, oxidative burst and dynamic expression profiles of ROS-scavenging enzymes of superoxide dismutase $(S O D)$, catalase $(C A T)$ and ascorbate peroxidase $(A P X)$ in 
response to Erwinia amylovora in pear (Pyrus communis L)," European Journal of Plant Pathology, vol. 147, no. 2, pp. 279294, 2017.

[38] L. Chen, S. Li, X. Guo, P. Xie, and J. Chen, "The role of GSH in microcystin-induced apoptosis in rat liver: involvement of oxidative stress and NF- $\kappa \mathrm{B}$," Environmental Toxicology, vol. 31, no. 5, pp. 552-560, 2014.

[39] Q. H. Huang, L. Q. Xu, Y. H. Liu et al., "Polydatin protects rat liver against ethanol-induced injury: involvement of CYP2E1/ ROS/Nrf2 and TLR4/NF- $\kappa \mathrm{B}$ p65 pathway," Evidence-Based Complementary and Alternative Medicine, vol. 2017, Article ID 7953850, 14 pages, 2017.

[40] R. H. Shih, C. Y. Wang, and C. M. Yang, "NF-kappaB signaling pathways in neurological inflammation: a mini review," Frontiers in Molecular Neuroscience, vol. 8, p. 77, 2015. 


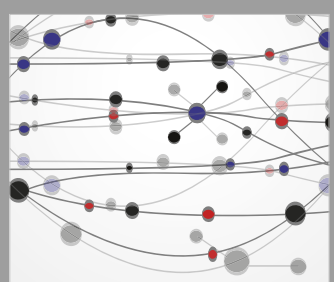

The Scientific World Journal
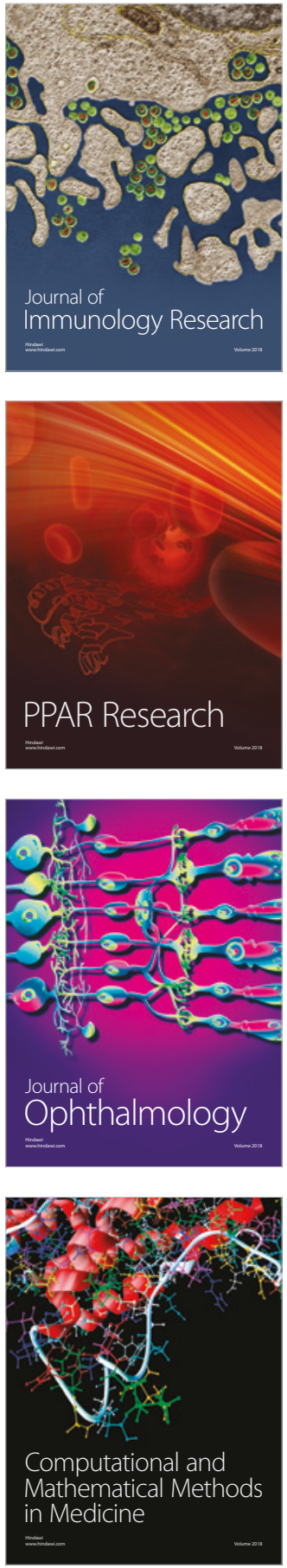

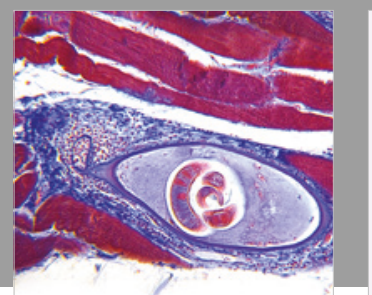

Gastroenterology Research and Practice

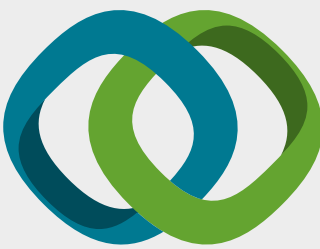

\section{Hindawi}

Submit your manuscripts at

www.hindawi.com
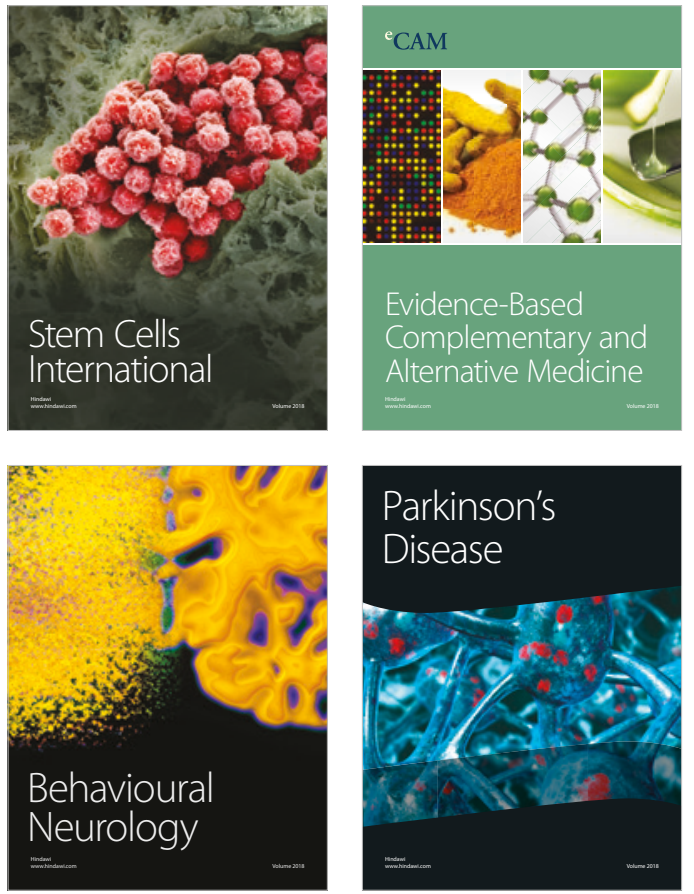

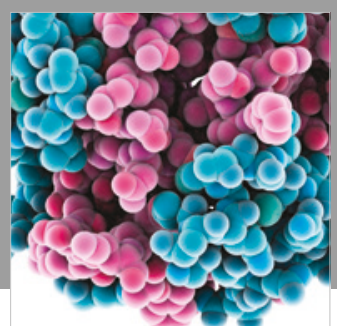

ournal of

Diabetes Research

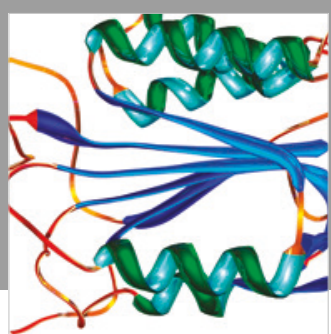

Disease Markers
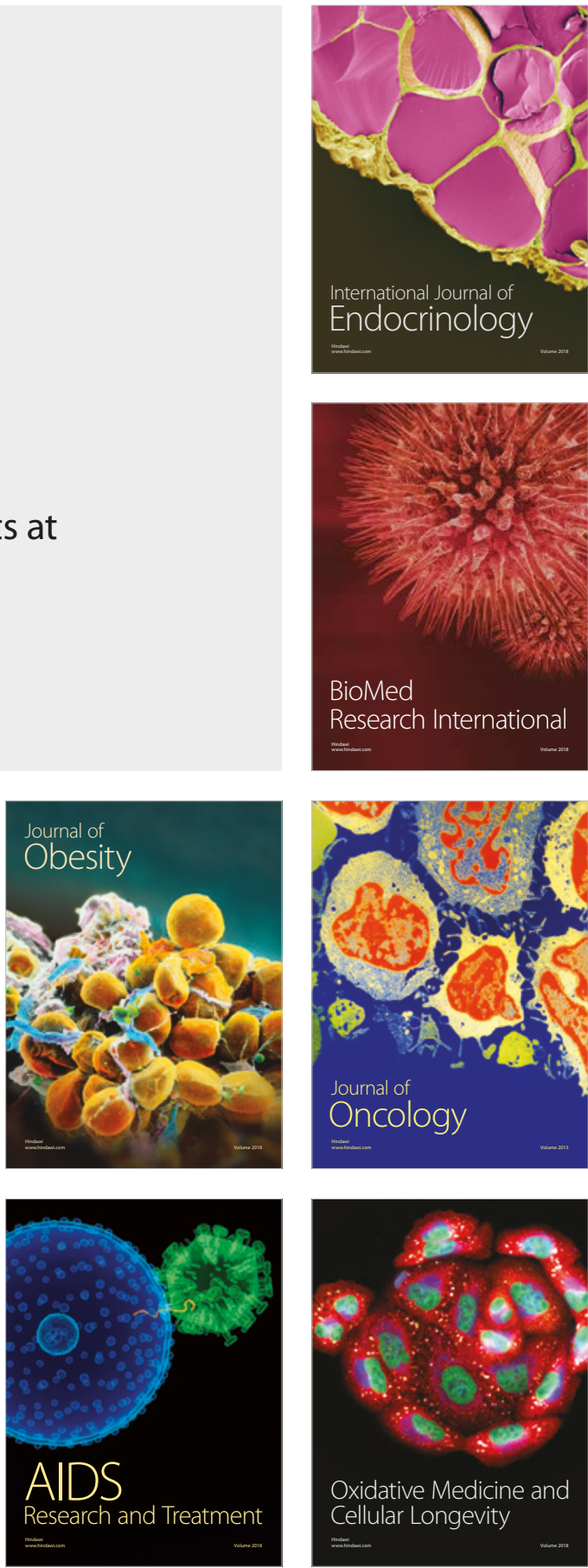